\title{
About One Method of Active Dynamic Damping
}

\section{Teshaev Muhsin Khudoyberdiyevich*, Yuliyev Ozod Olimovich, Oripov Zayniddin Bakhtiyorovich}

Bukhara Technological Institute of Engineering, Bukhara, Uzbekistan

\section{Email address:}

Muhsin_5@mail.ru (T. M. Khudoyberdiyevich)

*Corresponding author

\section{To cite this article:}

Teshaev Muhsin Khudoyberdiyevich, Yuliyev Ozod Olimovich, Oripov Zayniddin Bakhtiyorovich. About One Method of Active Dynamic Damping. American Journal of Management Science and Engineering. Vol. 2, No. 5, 2017, pp. 145-149. doi: 10.11648/j.ajmse.20170205.18

Received: March 31, 2017; Accepted: May 4, 2017; Published: October 24, 2017

\begin{abstract}
In this article questions of active clearing of vibrations of system are considered. The paper deals with the active damping of the system's oscillations. Considering that the system is constrained by servosvyazami, for a single-mass system it is proposed to perform servosviaz by changing the mass of the absorber. For this it is proposed to build a digital tracking system.
\end{abstract}

Keywords: Active Dynamic Damping, Oscillation, Amplitude, Frequency, Extinction, Servo-constraint

\section{Introduction}

In analytical dynamics the concept about the servo-constraints has been introduced by A. Beghen for the first time. The methods used by A. Beghen have gained the further development in P. Appel, A. Pshcheborsky, V. S. Novoselov, M. F. Shulgin, V. V. Rumyantsev, V. I. Kirgetov, G K. Pozharitsky's works, Do Shane, A. G. Azizov and others. In these researches much attention has been paid to generalization of the basic principles of dynamics on systems from a servo-constraints, to drawing up the equations of the motion, definition of reactions of mechanics servo-constraints proceeding from the general principles, and, a long time for servo-constraints the model of not releasing non ideal communications was accepted.

Distribution of methods of analytical mechanics on systems from servo-constraints was based mainly on the accounting of the features connected with not ideality servo-constraints, which is shown that for such systems, elementary work of forces of reactions of servo-constraints on the possible motions allowed by communications isn't equal to zero.

Despite importance of a research of the specified feature servo-constraints, annexes of methods of analytical dynamics to a wide range of specific objectives demand the account and other features connected with steady realization servo-constraints. Sh. S. Nugmanova's attention has been for the first time drawn to this circumstance. Being guided by the theory of parametrical release, and the theory of the compelled motions of the N. G. Chetayev's, A. G. Azizov has constructed the theory allowing to broaden the area of practical applicability of methods of analytical mechanics of system from a servo-constraints, including questions of their steady realization. The theory of creation of systems of the program motion created generally by works of A. S. Galiullin and his followers is close to systems from a servo-constraints.

Still A. Beghen noted that servo-constraints carried out not by means of simple contact, not passively, their realization is connected with use of different forces (electromagnetic, pressure of compressed air, etc.). Questions of realization servo-constraints were considered in Ya. N. Roytenberg, Ya. L. Lunts, V. V. Kozlov, A. G. Azizov, A. Akmukhammedov, R. M. Ziyatdinov's works and others. However, in these researches were considered or special cases, or at realization of servo-constraints ways of her realization weren't considered. Therefore, development of a method of realization of servo-constraints represents both theoretical, and practical interest.

To date, the dynamics of systems with servo- constraints devoted a significant number of studies. These include the works of A. Beghen [2], V. V. Rumiantsev [3], A. G. Azizov [4, $5,7]$ and others. In recent years, the theory of systems with servo- constraints began to be developed taking into account the release and the need for a sustainable implementation of the ratio of servo - constraints. These questions are reflected in a number of works of A. G. Azizov [4, 5, 7], based on the theory of parametric liberation, and the theory of forced motions [12].

A. G. Azizov [4, 5, 7] proposed an important constructive method for applications of finding the structure of reaction 
bonding forces, which ensures the stabilization of the system's motion relative to the variety determined by servo-constraints.

To systems with servo-constraints the theory of construction of systems of program motion [5] is close, created basically by works of A. S. Galiullin and his pupils.

In this paper, the question of the steady implementation of servo-constraints to a mechanical system with a dynamic absorber is considered.

It is known [1;2] that additional sources of energy are used to implement servo-connections. These energies can be either external or internal. However, according to A. Begen, «... it is impossible to distract from the way of implementing servo-constraints» [2]. Therefore, the implementation of servo-constraints using dynamic absorbers is considered.

\section{Formulation of the Problem}

We consider cargo strengthened on a spring with rigidity $C_{1}$, which makes forced oscillations under the action of a disturbing force

$$
Q=Q_{0} \cdot \sin p t
$$

acting on the object, or by vibrations of the foundation, according to law

$$
x_{0}(t)=x_{0} \sin p t
$$

where $x_{0}, Q_{0}$-amplitudes; $p$-frequency; $t$ - time.

Under the influence of the enclosed indignation, the object makes one-dimensional vibrations with amplitude [1]:

$$
a=\frac{Q_{0}}{C_{1}\left[1-\left(\frac{\omega}{\omega_{0}}\right)^{2}\right]}
$$

where $\omega_{0}=\sqrt{\frac{c_{1}}{m}}$ - own frequency of object. At $\omega \rightarrow \omega_{0}$ vibration of object essentially increase. It is required to define, under what conditions it is possible to extinguish these vibrations, having attached to cargo 1 on a spring with factor of rigidity $C_{1}$ and viscous damper with viscosity factor $b_{\Gamma}$ in cargo in 2 weight $m_{\Gamma}$. It means that, on system « Cargo absorber $»$ one is imposed servo-constraint [2]:

$$
x=0
$$

\section{Formulation of the Equations of Motion and Determination of the Reaction Force}

As servo-constraint's force operates on absorber, (A) moving [3] will look like:

$$
\delta x_{\Gamma}=0
$$

It is known [4; 5], that along with parities (1) parities also take place:

$$
x=\xi
$$

where $\xi$-parameter of clearing from servo-constraint. Zero value of $\xi$ corresponds to communication (1) or its differentiated form.

Differential equations of vibrations of system with absorber have following an appearance:

$$
\left\{\begin{array}{l}
m \xi+b_{\Gamma}\left(\dot{\xi}-\dot{x}_{\Gamma}\right)+C_{1} \xi+C_{\Gamma}\left(\xi-x_{\Gamma}\right)=Q_{0} \sin p t \\
m_{\Gamma} \ddot{x}_{\Gamma}+b_{\Gamma}\left(\dot{x}_{\Gamma}-\dot{\xi}\right)+C_{\Gamma}\left(x_{\Gamma}-\xi\right)+\frac{d m_{\Gamma}}{d t}\left(\dot{x}_{\Gamma}-\dot{\xi}\right)=R
\end{array}\right.
$$

where $R$ - servo constraints force.

We will set the task: to define, under what law to regulate force of reaction of servo-constraint $R$, that the servo-constraint (1) it was carried out stability.

Writing down the equations (4) in a kind:

$$
\begin{gathered}
\left(m_{\Gamma} \ddot{\xi}+b_{\Gamma} \dot{\xi}+C_{\Gamma} \xi\right)-\left(b_{\Gamma} \dot{x}_{\Gamma}+C_{\Gamma} x_{\Gamma}\right)=Q_{0} \sin p t \\
\left(m_{\Gamma} \ddot{x}_{\Gamma}+b_{\Gamma} \dot{x}_{\Gamma}+C_{\Gamma} x_{\Gamma}\right)-\left(b_{\Gamma} \dot{\xi}+C_{\Gamma} \xi\right)+\frac{d m_{\Gamma}}{d t} \dot{x}_{\Gamma}=R
\end{gathered}
$$

and from the second equation of system (5) we will define expression $\left(b_{\Gamma} \dot{x}_{\Gamma}+C_{\Gamma} x_{\Gamma}\right)$, i.e.,

$$
\left(b_{\Gamma} \dot{x}_{\Gamma}+C_{\Gamma} x_{\Gamma}\right)=-m_{\Gamma} \ddot{x}_{\Gamma}+\left[b_{\Gamma} \dot{x}_{\Gamma}+C_{\Gamma} x_{\Gamma}\right]-\frac{d m_{\Gamma}}{d t} \dot{x}_{\Gamma}+R
$$

Substituting (6) in the first equation of system (5), we will receive:

$$
\begin{aligned}
& \left(m_{\Gamma} \ddot{\xi}+b_{\Gamma} \dot{\xi}+\left(C_{1}+C_{\Gamma}\right) \xi\right)-\left(b_{\Gamma} \dot{x}_{\Gamma}+C_{\Gamma} x_{\Gamma}\right) \\
& +m_{\Gamma} \ddot{x}_{\Gamma}+\frac{d m_{\Gamma}}{d t} \dot{x}_{\Gamma}-Q_{0} \sin p t=R
\end{aligned}
$$

If reaction of servo constraint (1) to form under the law $[4,5$, 7]:

$$
R=m_{\Gamma} \ddot{x}_{\Gamma}-Q \sin p t+\frac{d m_{\Gamma}}{d t} \xi-k_{1} \dot{\xi}-k_{2} \xi
$$

where $k_{1}, k_{2}$ - some constants, that, substituting (8) in (7), we will receive the equations of the indignant motion of object:

$$
m_{\Gamma} \ddot{\xi}+k_{1} \dot{\xi}+\left(C_{1}+k_{2}\right) \xi=0
$$

Equation (9) is the differential equation with constant factors.

\section{Investigation of Stability}

We investigate on stability not indignant motion: 


$$
\xi=0
$$

corresponding servo constraint (1). For this purpose we will form the characteristic equation (9), which looks like:

$$
m_{\Gamma} \lambda^{2}+k_{1} \lambda+\left(C_{1}+k_{2}\right)=0
$$

Equation (10) is a quadratic with constant factors. Therefore stability of realization of servo constraint (1) (negativity of the real parts of roots of the characteristic equation) can be investigated by Hurvits's criterion [6]. For this purpose we will make a characteristic determinant (Hurvitsian):

$$
\Delta=\left|\begin{array}{llc}
m_{\Gamma} & C_{1}+k_{2} & 0 \\
0 & k_{1} & 0 \\
0 & m_{\Gamma} & C_{1}+k_{2}
\end{array}\right|
$$

According to Hurvits's theorem, the necessary and sufficient condition of negativity of the real parts of roots of the characteristic equation (a condition of asymptotic stability) for the equation of the second degree will look like [6]:

$$
\begin{gathered}
m_{\Gamma}>0, \quad k_{1}>0, \Delta_{1}=m_{\Gamma}>0 \\
\Delta_{2}=\left|\begin{array}{cc}
m_{\Gamma} & C_{1}+k_{2} \\
0 & k_{1}
\end{array}\right|=m_{\Gamma} \cdot k_{1}>0 \\
\Delta_{3}=\left|\begin{array}{llc}
m_{\Gamma} & C_{1}+k_{2} & 0 \\
0 & k_{1} & 0 \\
0 & m_{\Gamma} & C_{1}+k_{2}
\end{array}\right|=m_{\Gamma} \cdot k_{1} \cdot\left(C_{1}+k_{2}\right)>0 .
\end{gathered}
$$

Hurvits's conditions are led to inequalities:

$$
m_{\Gamma}>0, \quad k_{1}>0, C_{1}+k_{2}>0
$$

The conditions (11) express the conditions for the stability of the system and show that, the stability is ensured to ensure the stability of the system in relation to servo-coupling (1), under what conditions the constant coefficients, and the law of variation of the mass of the absorber. It should be noted that, under the conditions (11), there is some arbitrariness, which consists in choosing a way to implement these conditions. So, for example, if we assume that the absorber mass is constant, then from (11) we obtain conditions

$$
k_{1}>0, k_{2}>0 \text {, }
$$

which are provided by a suitable choice of fluid viscosity and spring stiffness.

\section{Investigation of Realization of Servo-constraint}

We will consider the problem of realization of servo constraint (1). As expression (8), force of reaction of servo constraint $\mathrm{R}$ shows depends on external disturbing force
$Q \sin p t$, from weight change of $\frac{d m_{\Gamma}}{d t} \dot{x}_{\Gamma}$ absorber (from jet force), from relative speed of absorber $m_{\Gamma} \ddot{x}_{\Gamma}$ and from coordinate and speed of change of a body (1). From works V. V. Rumjantsev [3] and also A. G. Azizov [4; 5] it is known, that an example of the systems, containing servo constraints, are watching systems. Therefore, for the decision of the put question we are offered to use electromechanical watching system ( EWS) [6].

The equation of motion of object (of cargo) with holonomic fixed constraints (1) will look like:

$$
\left\{\begin{array}{l}
\left(m_{\Gamma} \ddot{\xi}+b_{\Gamma} \dot{\xi}+C_{\Gamma} \xi\right)-\left(b_{\Gamma} \dot{x}_{\Gamma}+C_{\Gamma} x_{\Gamma}\right)=Q_{0} \sin p t \\
\left(m_{\Gamma} \ddot{x}_{\Gamma}+b_{\Gamma} \dot{x}_{\Gamma}+C_{\Gamma} x_{\Gamma}\right)-\left(b_{\Gamma} \xi+C_{\Gamma} \xi\right)+J_{g} \cdot i_{1}^{2} \cdot \frac{\ddot{x}_{\Gamma}}{r_{1}}=K_{m_{1}} \cdot i_{1} \cdot I_{1}
\end{array}\right.
$$

where $r_{1}$ - radius of a gear wheel, reformative a rotary motion in the forward; $J_{\Omega}$ - the moment of inertia of an anchor of the electric car (EC) a direct current of independent excitation; $i_{1}$ - transfer factor.

As the processes occurring in watching system are interconnected, to the equations of motion of object (of cargo) (12) should be the equations of other elements of watching system are attached. We will form these missing equations.

Usually gauges of measurement (GM) will transform kinematic parameters to pressure $[6,10,11]$. Gauges of measurement (GM) in which quality potentiometers are used, achogenerators, rotating transformers, sensors, etc., can be described by equations $[6,10,11]$ :

$$
\begin{gathered}
T_{1}^{D} \cdot \dot{U}_{1}^{D}+U_{1}^{D}=K_{1}^{D} \xi, T_{2}^{D} \cdot \dot{U}_{2}^{D}+U_{2}^{D}=K_{2}^{D} \dot{\xi}, \\
T_{3}^{D} \cdot \dot{U}_{3}^{D}+U_{3}^{D}=K_{3}^{D} \ddot{x}_{\Gamma},
\end{gathered}
$$

where $U^{D}$ - target parameter; $K^{D}$ - transfer factor; $T^{D}$ delay time.

Under the scheme of transformation of the joint venture, the received pressure will be transformed to codes [7]:

$$
T_{j_{1}}^{C \Pi} \dot{x}_{j 1}^{C \Pi}+x_{j_{1}}^{C \Pi}=K_{j_{1}}^{C \Pi} U_{j_{1}}^{D},\left(j_{1}=1,2,3\right)
$$

where $K_{j_{1}}^{C \Pi}$ - factor of transfer of the joint venture; $x_{j_{1}}^{C \Pi}$ target codes of the joint venture; $T_{j_{1}}^{C I}$ - delay time, also move on input COMPUTER.

The received codes on COMPUTER are processed and on an exit command codes [7] move:

$$
T_{1}^{L B M} \dot{x}_{1}^{L B M}+x_{1}^{L B M}=f_{1}\left(x_{\Gamma}, \ddot{x}_{\Gamma}, \xi, \dot{\xi}, \ldots\right)
$$

where $x_{1}^{L B M}$ - target parameters (codes) of COMPUTER; $T_{1}^{L B M}$ - time of delay of COMPUTER; $f_{1}$ - some function of the arguments.

The received command codes in transformer codes to pressure (TCP) will transformed to pressure [7]: 


$$
T_{1}^{\Pi K H} \dot{U}_{1}^{\Pi K H}+U_{1}^{\Pi K H}=K_{1}^{\Pi K H} \cdot x_{1}^{L B M}
$$

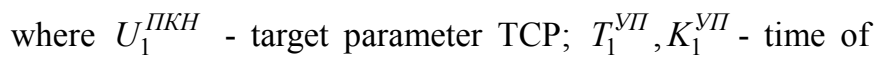
delay and strengthening factor.

The code converter in pressure (TCP) operates the amplifier-converter (AC), forming managing directors of pressure under the law [7]:

$$
T_{1}^{\mathrm{YI}} \dot{U}_{1}^{\mathrm{II}}+U_{1}^{\mathrm{YI}}=K_{1}^{\mathrm{YI}} \cdot U_{1}^{\Pi \Pi K H}
$$

where: $U_{1}^{\mathrm{VII}}$ - pressure on an amplifier-converter (AC) exit; $T_{1}^{V I \Pi}, K_{1}^{V I \Pi}$ - time of delay and strengthening factor.

To the received system of the equations (12) - (17) adding the equations of balance of pressure of a chain of an anchor:

$$
L_{1} \frac{d I_{1}}{d t}+R_{1} I_{1}+K_{w 1} \cdot \dot{i}_{1} \cdot \frac{\dot{x}_{\Gamma}}{r_{1}}=U_{1}^{y \Pi}
$$

where $L_{1}, R_{1}$ - inductance and active resistance of an anchor chain; $I_{1}, U_{I^{-}}$a current and pressure of a chain of an anchor;
$K_{w 1}$ - factor anti - EMF, we will receive the closed system of the equations (12) - (18).

If in system (12) - (18) instead of the equation (12) to take the equation:

$$
m_{\Gamma} \ddot{x}_{\Gamma}-Q \sin p t+\frac{d m_{\Gamma}}{d t} \xi-k_{1} \dot{\xi}-k_{2} \xi J_{\Omega} \cdot i_{1} \cdot \frac{\ddot{x}_{\Gamma}}{r_{1}}-K_{m} \cdot i_{1}^{2} \cdot I_{1}=0
$$

then, from system of the equations (13)- (19), the law of formation of operating influences (codes) from outside COMPUTER can be defined.

Along with the generalized model of watching system, we will consider the simplified model. For this we assume that:

$$
\begin{gathered}
T_{1}^{L B M}=T_{1}^{\Pi K H}=T_{1}^{V I \Pi}=L_{1}=0, \\
T_{j}^{D}=0 \quad, \quad T_{j_{2}}^{C I}=0,\left(\mathrm{j}=1,2,3 ; \mathrm{j}_{1}=1,2,3\right)
\end{gathered}
$$

Then, from system of the equations (13)- (19), under conditions (20) we will receive:

$$
\left.f_{l}+\frac{R_{1}}{i_{1} \cdot K_{1}^{Y I I} \cdot K_{1}^{\Pi K H} \cdot K_{m}} m_{\Gamma} \ddot{x}_{\Gamma}-Q \sin p t+\frac{d m_{\Gamma}}{d t} \xi-k_{1} \dot{\xi}-k_{2} \xi\right\}+\frac{K_{\omega} \cdot i_{1} \cdot \frac{\dot{x}_{\Gamma}}{r_{1}}}{K_{1}^{V \Pi} \cdot K_{1}^{\Pi K H}}
$$

If on COMPUTER, a part of watching system, we will form operating influences (codes) by the law (21), at assumptions (20), we will receive the equations (10), for which stability conditions of not indignant motion looks like (11).

\section{Conclusion}

If to consider the generalized model, i.e. not to consider a parity (20), the law of formation of operating influences $f_{1}$ can be certain by the numerical decision of system of the equations (13)- (19) by method of Zeydel [9]. For this purpose passing to final parities [9]:

$$
\begin{aligned}
& (\dot{I})_{1}=\frac{(I)_{1}^{N+1}-(I)_{1}^{N}}{h}, \dot{U}_{1}^{\mathrm{yI}}=\frac{\left(U_{1}^{\mathrm{YI}}\right)^{N+1}-\left(U_{1}^{\mathrm{YII}}\right)^{N}}{h}, \\
& \dot{U}_{1}^{\Pi K H}=\frac{\left(U_{1}^{\Pi K H}\right)^{N+1}-\left(U_{1}^{\Pi K H}\right)^{N}}{h}, \\
& \dot{x}_{1}^{L B M}=\frac{\left(x_{1}^{L B M}\right)^{N+1}-\left(x_{1}^{L B M}\right)^{N}}{h}
\end{aligned}
$$

system (13)- (19) we will lead to a kind:

$$
\begin{aligned}
& \left(I_{1}\right)^{N+1}=\frac{1}{K_{m} \cdot i_{1}}\left\{\quad m_{\Gamma} \ddot{x}_{\Gamma}-Q \sin p t+\frac{d m_{\Gamma}}{d t} \xi-k_{1} \dot{\xi}-k_{2} \xi+\right. \\
& \left.J_{я} \cdot i_{1}^{2} \cdot \frac{\ddot{x}_{\Gamma}}{r_{1}}\right\}
\end{aligned}
$$

$$
\begin{aligned}
& \left(U_{1}^{\mathrm{y} \Pi}\right)^{N+1}=L_{1}\left[\left(\frac{\left(I_{1}\right)^{N+1}-\left(I_{1}\right)^{N}}{h}\right)\right]+\dot{i}_{1} \cdot K_{w 1} \cdot \frac{\dot{x}_{\Gamma}}{r_{1}}+R_{1} \cdot\left(I_{1}\right)^{N}, \\
& \left(U_{1}^{I I K H}\right)^{N+1}=\frac{1}{K_{1}^{У \Pi}}\left[T_{1}^{У \Pi} \cdot \frac{\left(\dot{U}_{1}^{У \Pi}\right)^{N+1}-\left(U_{1}^{У \Pi}\right)^{N}}{h}+\left(U_{1}^{У \Pi}\right)^{N}\right] \text {, } \\
& \left(x_{1}^{L B M M}\right)^{N+1}=\frac{1}{K_{1}^{\Pi K H}}\left[T_{1}^{\Pi K H} \cdot \frac{\left(U_{1}^{\Pi K K}\right)^{N+1}-\left(U_{1}^{\Pi K H}\right)^{N}}{h}+\left(U_{j}^{\Pi K H}\right)^{N}\right] \text {, } \\
& \left(f_{1}\right)^{N+1}=T_{1}^{L B M} \cdot \frac{\left(x_{1}^{L B M}\right)^{N+1}-\left(x_{1}^{L B M}\right)^{N}}{h}+\left(x_{j}^{L B M}\right)^{N},
\end{aligned}
$$

The system (22) is solved numerically. Following values [10] thus were accepted:

$$
\begin{gathered}
\kappa^{\Pi К H}=26, T^{\Pi К H}=0,003 \text { сек, } i_{\Omega}=50, \\
T^{\mathrm{Y \Pi}}=0,01 \text { сек, } T^{L B M}=0,001 \text { сек, } K^{\mathrm{Y \Pi}}=26
\end{gathered}
$$

We choose the engine 2ПБВ 100L [11]:

$$
\begin{gathered}
\mathrm{I}_{\text {пом }}=25 \mathrm{~A} \mathrm{~K}_{\mathrm{T}}=10,8 \mathrm{мс} \\
\mathrm{J}_{\mathrm{g}}=13 \cdot 10^{3} \mathrm{\kappa} \cdot \mathrm{M}^{2} \mathrm{~K}_{\mathrm{w}}=5,75 \mathrm{Mc} \\
\mathrm{L}=0,8 \mathrm{м} \Gamma \mathrm{H}
\end{gathered}
$$

It is besides accepted: 


$$
\begin{gathered}
\mathrm{T}=1 \kappa г, \quad \dot{\chi}=3 \text { сек }^{-1}, \ddot{\chi}=4 \text { сек }^{-2} \\
\mathrm{~J}_{1}=2 \kappa^{2} \cdot \mathrm{M}^{2}, \dot{\eta}=2 \text { сек }^{-1}, \ddot{\eta}=2 \text { сек }^{-2} \\
\mathrm{r}_{1}=1 \mathrm{м}, \mathrm{h}_{10}=10, \mathrm{~h}_{11}=10 \\
\mathrm{~b}=1 \mathrm{м} \mathrm{F}=10 \mathrm{H} \\
\kappa=1 \mathrm{м} \mathrm{a}=1,5 \mathrm{M}
\end{gathered}
$$

The received numerical results differ from the theoretical results, calculated at assumptions (20), on 10-15\%.

The work was supported by the Fund for Fundamental Research F-4-14 of the Republic of Uzbekistan.

\section{References}

[1] Kolovsky M. Z. Nonlinear theory of vibro- protectoral systems. Moscow, Nauka press. 1982.-487p. (In Russian).

[2] Beghen, A. Theory of gyroscopic compasses. Moscow, Nauka press. 1967.-192p. (In Russian).

[3] Rumjantsev V. V. About motion of operated mechanical systems//The Applied mathematics and mechanics, 1976. №. 40, Issue 5.-pp. 771-781 (in Russian).
[4] Azizov A. Г. About the equations of dynamics of systems with servo constraints. 1975. Issue. 476.- pp. 67-75 (in Russian).

[5] Azizov A. G. Applied problems of dynamics of operated systems. Tashkent, 1980.-23 p. (In Russian).

[6] Bases of designing of watching systems / Under N. A. Lakota's edition. Moscow, Mechanical engineering press, 1978.-391 p.

[7] Teshayev M. KH. About implementation servo-constraints by the electromechanical watching system / Izv. Vuzov. Mathematics. 2010, No. 12. - Page 44-51, English-language version: Russian Mathematics (Izvestiya VUZ. Matematika), 2010, 54: 12, 38-44.

[8] Merkin G. D. Introduction in the stability theory. Moscow: the Science press, 1987.- 304 p. (In Russian).

[9] Boasters H. C., Zhidkov N. P., Kobelkov G. M. Numerical methods. Moscow: a Science press, 1987.- 600 p. (in Russian).

[10] Basharin A. B., Postnikov Yu. B. Examples of calculation of the automated electric drive on the COMPUTER. Leningrad: Energoizdat press, the Leningrad branch. 1990.- 512 p. (in Russian).

[11] Mikhaylov O. P. Island the Automated electric drive of machine tools and industrial robots. Moscow: Mechanical engineering press, 1990.- 403p. (in Russian). 